\title{
Autumn in a New Residential Area
}

"And the window could be opened so that nothing remained between the world and the room." (Autumn Ball, p. 31)

This article compares one of the most translated Soviet-era Estonian novels, Mati Unt's Autumn Ball (1979), and the film of the same title (2007, director Veiko Õunpuu). According to a number of sources, Unt's novel contains the first manifestations of postmodernism in Estonian literature (e.g. Annus 2000: 778; Epner 2001: 497, Viires 2008: 61), and we can regard the film as a certain turning point in the development of Estonian cinema. It has received several awards abroad and is probably one of the internationally best-known Estonian feature films.

The focus of the current article moves from the film Autumn Ball back to the book Autumn Ball. One theme linking these focuses is the environment in which the plot of Autumn Ball(s) unravels: the space where the autumn ball takes place. The location of both the film and the novel is a new residential area in Tallinn. In the novel, this is the tower-block district called Mustamäe, which was started in the 1960s; the action of the film occurs in a similar satellite district, Lasnamäe, mainly built in the 1980s. During its construction, Mustamäe was characterised by an optimistic and positive attitude (cf. also Viires 2003), whereas the attitude towards the Lasnamäe residential district contained a negative undertone from the very beginning. This obvious emotional negativism is essentially there also in Veiko Õunpuu's film, where practically nothing good or beautiful is ever seen in the district. The aspects of visual enjoyment that Lasnamäe offers - expansive vistas, light etc. - have been totally abandoned, and thus the whole environment is characterised by a negative aesthetics.

The Mustamäe in Unt's Autumn Ball does not present such straightforward attitudes. Autumn Ball was influenced by architec- 
tural discussions about a friendly and individualised urban environment and the novel, in turn, interfered in these discussions (Lapin 1980, cf. also Kurg 2010). The attitude to the residential district varies according to the character: there is aesthetic pleasure, discomfort and feelings of alienation, sharp interest and indifferent pragmatism. Most characters have an experience of a different living environment: a wooden slum, an area of private residences and a house in the country. Only the boy Peeter was born and grew up in Mustamäe.

The fact that Mustamäe in Unt's Autumn Ball is something much more meaningful than simply a place of action, maybe even more significant than all the protagonists put together, was acknowledged immediately after the novel was published (e.g. Jõgi 1982; Mutt 1986). ${ }^{1}$ The focus on Mustamäe was later augmented in articles by Epp Annus and Piret Viires (Annus 2006; Viires 2003). In sum, the place, a real place, tends to overshadow the text of Autumn Ball.

The film Autumn Ball lasts slightly more than two hours. Its reception so far has mostly been descriptive rather than interpretive. The initial bewilderment of Unt's fans soon vanished as it turned out that, besides the identical title and the same number of main characters, whose names occasionally coincide or are at least similar, there is nothing much in common between the book and the film.

The Estonian-language homepage of the film offers a loose connection between the book and the film: "The movie is inspired by the book "Autumn Ball" by Mati Unt..."2 The same text appears to the patient viewer also in the final credits, after the rest of the text has run past, and continues: "....and dedicated to all the men with gentle heart and weak liver who stand alone in the night in underwear." The book might just as easily have inspired a painting

\footnotetext{
${ }^{1}$ Mustamäe has in fact been called the novel's collective protagonist in the annotation of the book (Unt 1979: 184).

${ }^{2}$ See http://www.sygisball.ee/et/film/about/ (accessed 11 January 2010). The note is missing in the English version.
} 
SARAPIK

or a piece of music, called Autumn Ball, and probably nobody would have bothered with finding any direct isomorphic connections.

Lasnamäe as the place of action of the film was clearly a conscious choice: it has a sharper meaning in the local socio-cultural context and stronger associations, offering views with more lucid emphasis in the visual (and international) plan and other environmental opportunities. That particular aspect of the film gathers all of the post-socialist new huge residential areas under Lasnamäe; Lasnamäe does not differ from other similar districts, but becomes their symbol.

Changes in characters that often depend on a kind of shift or even on mirror symmetry seem to try to break, rather than confirm, connections with Unt's text: the boy Peeter is replaced by the girl Lotta, the poet Eero by the writer Mati, and the hairdresser August Kask becomes Augusti Kaski of Finnish origin. The names of the other three main characters remain the same: Laura, the architect Maurer and the doorman Theo.

The book begins with expectation and a sense of danger. This is repeated in the last line of a Viivi Luik poem, which is also the epigram, as well as in the first sentence of the text - "Something was bound to happen" - immediately followed by mild comical bits that dispel expectations and anxiety: "Yet the autumn brought an extremely bounteous harvest of mushrooms /---/. There were too many apples, too; they kept falling into the grass all through the night, the canneries and juice presses could not cope with the enormous quantities of them /---/" (Unt 1985: 3). The beginning of the film, on the other hand, leaves no doubt about the mood: the figure of a man shivering on a balcony, a grim urban picture and a sky filled with black clouds and black birds.

In the book, the surroundings are observed only by the hairdresser August Kask through his telescope, whereas most views of the town in the film - from a balcony and a window - are presented through a telephoto lens. This method seems to bring the distant nearer, but by changing perspective also reduces the spatiality of whatever is far away, compressing the distance between the objects.

We could point out more similar comparisons, but that would not be quite correct or necessary. We have two Autumn Balls; the film 
was allegedly inspired by the novel, although certainly not only by its text, but by much else as well.

In what sense then are they essentially different? At least a couple of significant differences emerge in reading and watching.

\section{1.}

The film Autumn Ball is perceptibly, visually real, corresponding to our experience, and this includes the events as well. The often described anxiety and sense of unease which keep haunting the viewer after seeing the film are caused by the extreme reality of the fictional world. The viewer is unable to escape this and is sucked into it for at least two hours. The sequence of events unravelling in the film reality is loosely connected, and does not seem causal or determined by the preceding events. Characters in a world like this are alone, on their own. They are not linked with any common activities, just the same environment. All of the characters have lives of their own before and after the events, but we are not familiar with those lives, and they don't necessarily have anything to do with Lasnamäe: Lasnamäe is a coincidence in the characters' lives.

The construction of the novel Autumn Ball, on the other hand, seems highly regulated. Six moments in time have been chosen, presented in a certain sequence through the eyes of the six characters. These characters could have easily been picked at random, but as the plot lines come together in the final part of the book, and separate encounters have an impact on the following events, there is not much room for chance.

At the same time, Unt's book also presents a number of sensory experiences. In the text Unt uses the largest number of words denoting colour of any of his works, and we would probably reach the same result if we listed all the words indicating the experience of smell, sound or touch. Sensory experiences are scattered as innumerable fragments throughout the novel, but they do not form a uniform and smooth text reality. The fictional world is persistently shattered by the insecurity of the characters and the reader regarding its reality, and the possibilities offered by the storyteller that everything is somehow different and that both the reader and characters could 
SARAPIK

easily vanish from it at any moment. The reader feels uncertain because he cannot be sure what the next bits of text are going to offer (how the story will proceed and who exactly is presenting it); from the first pages onwards, the characters' relationships to the fictional world are characterised by doubts about the existence of themselves and their surroundings.

The uncertainty of existence is made clear at the very beginning of the novel, when the former tenor Mortenson, known as Marino Marini, vanishes into thin air in the middle of the railway platform in the town of Valga. "What's gone is gone, his friends decided, their thoughts taking a fatalistic turn /---/" (Unt 1985: 5). In the afternoon, the former opera singer finds himself deep in Latvian territory, in a village cemetery $36 \mathrm{~km}$ from the place where he disappeared. The anxiety of expectation is simultaneously created and crushed. The influence of sentences that evoke alienation is dispelled by somewhat absurd fragments.

The reader therefore faces a world where nothing is quite certain. In this world, the characters must constantly secure and prove their existence. The new residential district Mustamäe, which has no constant history, needs the same kind of security. One method of confirming the environment and people are sets of facts in the text. Mustamäe is presented through a set of details about distances, ancient history and ground surface (by the architect Maurer). Closer objects are recreated by their recounting (by Arnold Kask) and by just naming them (by Peeter). It is exactly through naming that Peeter builds up a safe environment around himself, a room where he need not be afraid even of thunder.

The situation is made more complicated by words denoting things that do not seem to exist. Peeter thus reaches theologically almost competent proof that God and the devil do exist: "Of God, everyone knew that He didn't exist. Yet He was spoken about all the time. They wouldn't have talked so much about something that didn't exist" (p. 33). And: "But the Devil exists after all, Peeter suggested. He gets talked about even more often than God. He doesn't exist either, Mother explained, 'devil' is just a very bad and horrid word. /---/ Why is it a dirty word then, if it doesn't mean anything? It means a very bad thing. What kind of thing? The Devil, exclaimed 
Mother, totally exasperated. I see, said Peeter, that means the Devil exists" (p. 34).

For Peeter, existence is confirmed by words and verbalisation, whereas for others, existence can be confirmed by an image: "Theo had got so used to looking at himself in the mirror that he sometimes felt insecure in a room with no mirror /---/. Sometimes he was afraid he might not exist at all because there was no proof of his existence" (p. 91). The existence of the architect Maurer, on the other hand, is proved to a benevolent militiaman by photographs found in his pocket: "The militiaman compared Maurer to the photographs. He did it very thoroughly, comparing him with each picture separately, although all the pictures were exactly alike." Satisfied by the similarity, the militiaman salutes Maurer and lets him go (p. 51).

The reader is therefore confronted with the possibility that all the characters could vanish at any time, because at first sight the only real thing seems to be Mustamäe itself. However, even this sense of certainty disappears quickly. The chance that there might be something else behind the door or window of an apartment besides what we think is there is constantly in the air. The constant recreation of a safe place, a home, does not however mean that everything outside it follows the efforts that produced existence. Thus the following picture could emerge at any moment: "Mustamäe had disappeared. The whole world had disappeared meanwhile. A grey nothingness stretched before them" (p. 71). The visible and seemingly existing world outside the apartment thus lives its own life: houses are breathing (p. 39), the building panels wilt in the evening (p. 9) and the huge boxes slumber in melancholy (p. 105).

This kind of non-existence, the possibility of non-places (and probably also non-time) is typical of Unt's Autumn Ball. We learn about the previous lives of all the characters, where they come from, although it is no longer possible to return there. The architect Maurer can never go back to the cosy slums of his childhood. Finding themselves in Mustamäe is not accidental; this seems to be predestined for all of them. However, people can easily disappear, go somewhere else, usually far away, to the other end of the world. An example: early in the morning after Eero and Laura meet, the piano player who is Eero's only chance to find Laura's house, leaves for 
SARAPIK

Sri Lanka. Equally, someone from a non-place and non-time, or from the other end of the world, can turn up in Mustamäe. One such person is from Tierra del Fuego, and that person annoys the others by endlessly singing like the vanished opera singer Marino Marini. And it is the initially vanished Marino Marini who reappears and causes a car crash in which August Kask gets killed.

Eero's wife leaves him in the evening when they have a party to celebrate their move to Mustamäe. After that, Eero manages to track her down only once, after which she disappears into the unknown, and we never hear of her again. This constitutes one of the essential differences between the film and the book: in the film, the writer Mati climbs on rubbish containers outside his wife's window and gets a look at her. The film can end with the wife returning, whereas the book only offers an encounter with another woman, Laura.

Let us here recall the words of Viivi Luik, who said that before Unt wrote his Autumn Ball, Mustamäe did not exist (Luik 2005: 779). Or to be precise, it did exist, but its inhabitants were invisible; they could not have been imagined. Perhaps we could say that Mustamäe was missing in the collective consciousness, but it arrived there through Unt's novel, or perhaps even more through the discussions that arose about the new residential districts. One of the foundations of identity - memories linked with a place - was precisely what the Mustamäe inhabitants, largely from outside Tallinn, did not have. Mustamäe's existence is thus not created by the contemporaries of Autumn Ball and not by its characters, but by writing about it, even mentioning Mustamäe in the papers, repeating the name over and over again. Mustamäe is not created by the daily experience of its inhabitants, because it is uncertain, or by daily life, because the environment is hostile. Mustamäe therefore needs to be constantly recreated and its name repeatedly mentioned. This is done in the novel by the architect Maurer, thus continuing his initial role as the creator of the residential district but, as was already noted, the boy Peeter does the same thing. Maurer achieves this by amassing facts on various levels, Peeter simply by putting his direct surroundings into words. 
Autumn in a New Residential Area

\section{2.}

The reception of Unt's Autumn Ball when the novel first appeared focused on its human relations: relationships and solitude, contacts with the environment (the big city and the new residential district), and on Unt's style of writing. The next stage was positioning Autumn Ball on the modernism-postmodernism scale. Problems connected with the place of action, e.g. Mustamäe as a separate and independent character, and how the protagonists experience their environment, have again emerged in recent years (see Viires 2003; Annus 2006).

An interesting nuance is the connection between windows and watching mentioned by Epp Annus. Windows indeed play a crucial role in Autumn Ball; in the novel, it is the hairdresser August Kask who mostly counts and observes them, although all of the characters have their own relationships with windows. Still, first of all, the function of the window itself is contradictory, as shown by Epp Annus: people look out of the windows and light comes in through them, and the windows themselves are also watched and counted. One possibility is to consider Autumn Ball as a journey from empty black windows towards lit ones (see also Annus 2006: 112). The windows thus constitute a sign that the buildings are alive, or even act to revive them, thus making them cosy and human. The rhetorical connection of windows and eyes is close and Unt makes use of this ("The giant boxes were having a melancholy nap /---/. Their hundreds of eyes reflected a listless question" - p. 106). In the novel Autumn Ball, the windows, especially lit windows, on the whole appear in a positive key, unlike for example the doors, which may be misleading. Transparent doors turn out to be the worst elements, as they have betrayed their protective function ("There was something ambiguous about doors. They were smooth but mysterious" - p. 52). There are no fears in the book associated with windows - that you can be seen, watched and caught. A different experience between living lower and higher up is also evident. In the higher apartments, the inhabitants are not really threatened by anything, as their relationship with the outside world is inevitably distanced. 
SARAPIK

In his treatise On Painting (in Latin in 1435, in Italian in 1436), the Renaissance humanist, architect and painter Leon Battista Alberti wrote that a picture should represent the world as if you were looking at it through a window: "First of all, on the surface on which I am going to paint, I draw a rectangle of whatever size I want, which I regard as an open window through which the subject to be painted is seen; and I decide how large I wish the human figures in the painting to be" (I.19, Alberti 1991: 54). Then, according to the size and proportions of the depicted people and space, the artist determines the horizon and a point of convergence.

Here, the passive and active double essence of the window is augmented further: the window lets through rays of light: it is transparent; on the other hand, a window is a medium that requires the glance to be active. Alberti emphasises the viewer's intention by adding a possibility of a choice: the painter chooses what is visible through the window (for the viewer).

Together with the disappearance of realistic depiction in painting, the metaphor of "Alberti's window" retreated, but reappeared via photography, film and television. These three have the function of a window into the world, bringing the unattainable closer, both spatially and temporally. Or they place viewers in the middle of other people's lives, and take them where they otherwise could not go.

The window as a means of connecting different rooms, depicting transitions and oppositions, is naturally a charmingly common motif in films, theatre and pictorial art, but also in literature. Splendid window games, for example, have been analysed on the basis of Gustave Flaubert's Madame Bovary (Frank 1991: 16-18). Unt's Autumn Ball clearly falls into the same category. The window's variety of functions in Autumn Ball is impressive: the book describes the views from the windows of all the characters; and the TV screen and traditional painting constitute the Alberti-like windows that compete with the real ones. For Peeter and Arnold Kask, the window is a means of seeing outside, into somebody else's space; for Peeter, it is also a wall that separates his home space from the rest of the suspicious world. Both observe, but at different distances (Kask has a telescope, while Peeter prefers to look at smaller and closer things). The architect Maurer and Eero represent the "aesthetic view", which, 
however, does not emerge by itself, ready-made (it is not offered by the district itself); it requires an effort, casting something else aside or not noticing it. Eero's view is synaesthetic: he can perceive his surroundings also by means of smells and sounds coming in from the window. Maurer, on the other hand, links the view with knowledge. For Theo and Laura, looking out of the window constitutes a type of replacement activity, a passive way of existence; standing at the window, they seem to be looking, but at the same time they do not see what they are looking at, an activity that helps to collect their thoughts, focus on what they have seen on television, recall incidents in their lives (Laura) or analyse astrological predictions (Theo).

All these different views thus emphasise the difference between looking and seeing: looking is an intentional activity, consciously directing your glance towards something, but the result might not be actually seeing something, let alone seeing and understanding. Seeing does not occur simply via the glance, it must include learning, finding something out, which involves all of the senses. Looking presupposes an intentional glance, whereas seeing does not.

It should be clear from the above that the presentation strategies of the environment in Unt's Autumn Ball are rather unique. The significance of looking, watching from the window and from a distance, is often emphasised, and therefore we are left with the dominant impression of a distanced point of view, from where the viewer observes tiny human figures bustling about in the street or going about their business behind the windows of the house across the street. This is how Mustamäe is seen by Arnold Kask, Peeter and Maurer, and the reader gets an idea of what they see. The hairdresser Kask's desire to witness various depravities of life is his greatest desire: "He had feared, or hoped, to see Egyptian nights, pornographic delights, murder, rape, dances at least, birthday parties, or modest family love scenes. But he sustained a disappointment in this telescope. So plentifully provided with the potential for evil in the daytime, seemingly so minutely prepared for murder and incest, people had turned tame after the sun had gone down" (p. 73).

A few years before Autumn Ball was published, Finnish TV devoted one season to Alfred Hitchcock's films. I have no idea whether Rear Window (1954) was among them or whether Mati Unt 
SARAPIK

saw that film, but it is quite likely. For the protagonist, the photographer Jeff, life observed from his window replaces his own inactivity due to his broken leg, the lack of a television and of life itself. The neighbours' sins and virtues are revealed through the window, initially offering mere entertainment, but when events unravel, a murder is witnessed. Glances through the window, the double act of looking and watching (the viewer sees the photographer, then his glance through the lens, then the presumed murderer and the murderer's return glance), the meeting of the eyes of the observer and the murderer, mutual understanding and recognition, all make this film a classic of analysing looking and showing. Hitchcock's film is the archetypal text of window-watching and August Kask seems to be Jeff's possible reverse figure: he simultaneously desires and hates crime, depravity and filth, and cannot experience a single positive emotion. The lack of discovery and the lack of the hoped-for murder cause suffering. Besides, through watching, Kask has no power over the people he is looking at. As already noted, the Autumn Ball characters do not mind being watched through windows. For Laura, too, the fact that someone (i.e. Kask) is watching her from the opposite house is of little importance. (In the same watching scene, Kask on the other hand tries to focus all the possible power of persuasion into his glance.)

As the first peculiarity of the novel, we could point out doubts about the existence of the text reality, and also the possibility that whatever exists might disappear at any moment. Considering this, the window views of the characters indeed resemble the windows of Alberti. Although the characters do not choose what is shown through the rectangle, the narrator chooses for the reader.

The difference between watching television and watching from windows therefore disappears: Arnold Kask watches the windows across the road with just as much enthusiasm as Laura watches the TV series Cunningham. Thanks to the fact that the narrative of the series runs parallel to other activities, its characters become just as real or unreal as the text world. 
In the film Autumn Ball, people also look out of windows a lot, and twice they look inside. This kind of looking is similar in the film and in the book in that the view from the window is always linked with a character, is always somebody's view. The views have a purpose; they are not separated from a specific person.

However, there are several significant differences between the film and novel. The variety of window views in the film is considerably smaller. The viewer can share what a character happens to see and generally this is Lasnamäe, either in grey daylight (not one scene has any sunshine) or in nocturnal dampness and rain. Some views are quite extensive and others more closed, but there is no watching or counting of the windows in the opposite house. A few times people also look in: Mati standing on a rubbish container and staring in through the window at his wife and another man; and in another scene we see the poster-beautiful family of the film director who has given Laura a lift. In both these cases, the window clearly separates two fictional spaces: the viewer cannot cross the border. The same relationship occurs in the film between Laura and television; we learn about the series she is watching, but the events develop separately.

In addition to the views from the windows, there are many other types of looking in the film. Just as the architect Maurer watches the moving cars in the main thoroughfare, Lotte stands on the balcony observing the surroundings, and Augusti Kaski stares at the children from behind a kindergarten fence. Two features thus emerge: looking as such is important; the manner of looking does not depend on who is looking at what and how (i.e. by means of what). The aim of such looking is primarily to show what a character might see. Secondly, different characters are linked and the spatiality of the surroundings are created by looking. Views from the window bring Lasnamäe inside and do not allow the viewer to forget its existence. Unlike Unt, there is no difference between windows and doors; the first do not become independent as a rhetorical figure. Therefore, what matters is not looking as such, but showing the looking. 
SARAPIK

As already noted, analyses of textual or written space usually differentiate between the distanced manner of presentation, which primarily uses the sense of sight, and the reliance on bodily experience, where the whole body participates in spatial perception through touching, the sensation of pain and inner functioning, and does so just like looking, or even more so. In the first case, the positions of the subject and object - the environment and its perceiver - are mostly distinguished; on the other hand, they can mix and blend. The other senses - hearing, smell and taste - can blend both with the distanced and the bodily spatial experience. There are few literary texts that persistently use either one or the other type of spatial experience. A point of view can alternate within one text depending on the events, characters or moods.

One of the most common ways to physically perceive a town is of course by walking. Epp Annus noted that Autumn Ball has a lot of looking and watching, but little walking. Mustamäe is not really suitable for walking and is thus quite a hostile environment (Annus 2006: 112-116). At the same time, she neglected to mention a fact that clearly supports this claim: the car crash following August Kask's walk. Kask prefers to walk outside town, but the approaching winter to some extent conciliates him with the city. This is the first time during the period set in the novel that Kask exchanges looking at Mustamäe for walking around there, because snow has just fallen and purified the town, "covering the city's trash and foul refuse" (p. 177-178). The freshly fallen snow creates a new distance from the previous habitual environment, and makes people perceive it differently. However, replacing watching from a distance with walking results in the death of the walker.

At the same time, it is crucial that looking is not the only way to experience Mustamäe for any of the characters. This is not the only way even for the most dedicated watcher, August Kask. He equally loves to eavesdrop on other people's lives, and other senses help as well: "Sometimes August Kask stood at the window, staring up at the sky and getting some air. His nostrils would move erotically. He smelled death: carbon dioxide, sulphurous gases, soot, dust, strontium, pesticides and lead. His nose was sensitive and he knew what he was looking for" (p. 43). 
If we look more closely at the different ways the characters perceive the environment, we see an amazing variety and diversity. People look from a distance and from nearby, from inside out and from outside in, from above and from below. The distanced glance blends with the almost animal aliveness of the visible artificial objects. The houses are not just seen, measured, counted and touched, but are also perceived both psychically and somatically, they are heard and smelt, and they are alive themselves and constitute home for undetermined creatures. Microscopic sensations alternate with macroscopic, rational knowledge, with emotional bursts of feeling; Mustamäe is racked by time and the weather. It never quite emerges as a whole.

There is thus no clear opposition between the seen and the experienced environment. It would be more precise to say that the description of the environment in Autumn Ball is characterised by polyphony and polylogy, by a constant changing of different plans and points of view. Here, logical and bodily reception of space blend with looking, although they do not form any particular shape, but keep disintegrating, alternating, transforming into one another.

\section{3.}

As I mentioned before, the scenes in the film seemingly follow one another quite randomly, and there appears to be a possibility of realigning them differently, at least in the viewer's mind. The book, however, offers no such possibility. The six characters are united by a clearly established temporal framework (from September, the edge of summer, until December, the edge of winter) and common environment, where their stories unfold and intersect. The parallel aspect of the stories is confirmed by six shared moments in time, framed by either a season or weather: early autumn, thunder, fog, late autumn, the first snow and winter. The first two parts/times are presented in a certain sequence of characters; the first change of sequence appears in the third part, and a greater shift follows in the second part of the novel. There are, after all, 36 parts. It is difficult to believe that this is quite accidental: Eero lives on the sixth floor; August Kask and Laura on the ninth or sixth ("The sixth floor, let's 
SARAPIK

stick to the sixth floor, Eero thought, there must be a reason why that occurred to me. Six. $1+2+3$, Eero kept thinking" - p. 172.) In a review after the publication, Andres Langemets recognised an allusion to Bulgakov, finding that "Unt stops narrating where Bulgakov starts", and that "no magic powers directly interfere in Mustamäe scenes or, rather, they never materialise" (Langemets 1980: 129). It's true, despite the connection between the events, the causal development and predictions offered ironically (plus promises of demons), that we do not perceive anything supernatural.

The Bulgakov-like ending mentioned above is of course the death of Arnold Kask in a car crash. The driver is the singer Marino Marini, who has vanished without a trace. This is the scene where almost all the characters, although they do not know one another, meet. Eero finds Laura, August Kask finds (a morally deserved) death, Maurer finds a new activity for himself for the future, and Theo finds a solution concerning his worries about the world of criminals. The time ends for all of them here; they have no future outside the text of the book, except perhaps for Maurer. There is no chance for their lives to change, and no chance for the Mustamäe autumn to be anything but a passing episode in life.

The similar text strategy is a good example of what Joseph Frank has called the spatiality of the text itself, and what should be kept apart from the representation of space or textual space. Frank considers spatial texts those that gather in one moment of time activities which can be perceived simultaneously but not in connection with one another. When temporal sequence and causality are missing, the reader must join these activities spatially. Making the text spatial occurs by the above-described means: parallel stories and the fragmentary nature of events, no clear beginning and a narrative with no ending. Events have to be constructed from fragments, which are scattered all over the novel and may be separated by hundreds of pages (see Frank 1991: 18ff).

The autumn in the film does not change; it is grey and overcast. There is no summer before it or winter afterwards, no definite 
temporal borders. Unt selected six segments of time in sequence, whereas the film seems to have fixed on only one time. This seems to be the beginning of winter - traces of the first melted snow rather than late autumn, probably one of the most unpleasant times of year, where everything is revoltingly muddy, dark and damp. The sodden environment as a place of action visually links the entire external space even better than Lasnamäe. The environment in the film, as mentioned above, is highly perceptible, synaesthetically emphasising the space that is perceived through different senses and the body. The experiences of the senses are enlivened by several methods, for example contrasting Maurer's purist-aesthetic surroundings with Mati's filthy room full of scraps of food and drink. The frequent repeating of the autumnal sodden dampness serves the same kind of synaesthesia. The physical experience is enhanced by walking at night, in the rain and through wastelands, and by varying the way of walking, staggering and stumbling. One method is the clothing of the characters: the half-naked Lotte on the balcony in the rain, and Mati falling asleep not quite undressed, adjusting an illfitting garment: scenes with words that inevitably associate with our daily experience. As a result of all this, an extremely compact, uniform and hopelessly unchanged environment emerges. This, in turn, is emphasised by distances shortened by the lens, or general views that have been united into a compact whole by means of a wide-angle lens. Grey days alternate with dark evenings full of circles of streetlights that dissolve in the damp. More clearly delineated is only the last day, which seemingly brings all lines of action to some sort of ending, without however gathering the six characters in one place and uniting them through one event, as does Unt. In the novel, the text is made spatial by parallel stories integrated with the moments of time shared by the six characters, whereas the element in the film that makes the narrative spatial is the environment Lasnamäe.

There is no chance that Lasnamäe will disappear or change; it is always there outside the windows of the inhabitants, inexorably accompanying the characters outside, compressed by the telephoto lens. Time, too, is compressed and halted, and there is thus no need to determine it more precisely. There is just one overcast unchanging 
SARAPIK

season, and the entire depicted material environment - items and clothing - hopelessly mix the Soviet era with today.

$*$

In conclusion, we can agree with the often expressed thought that, both in the book and in the film, the residential districts - Mustamäe and Lasnamäe - become as crucial as characters. The same role could of course easily be taken by any other similar district in the world. The difference between the two texts reflects the time that passed between them, the different authors' positions, a different sense of reality and different ways of presenting the environment. What unites them besides the title? Maybe the fact that all that is left is the autumn and the residential district.

\section{References}

Alberti, L. B. 1991. On Painting. Trans. by Cecil Grayson, introduction and notes by Martin Kemp. Harmondsworth: Penguin.

Annus, E. 2000. Postmodernism kui hilissotsialismi kultuuriloogika. - Keel ja Kirjandus, No. 11, 769-780.

Annus, E. 2006. Jalajäljed ja pilgud. Mati Undi Mustamäe. - Looming, No. $1,112-123$.

Epner, L. 2001. Proosa uuenemine kodumaal. - Annus, Epp; Epner, Luule; Järv, Ants; Olesk, Sirje; Velsker, Mart. Eesti kirjanduslugu. Tallinn: Koolibri, 478-500.

Frank, J. 1991. The Idea of Spatial Form. New Brunswick: Rutgers University Press.

Jõgi, M. 1982. Sügisballi retseptsiooni mõnest tahust. - Kirjanduse jaosmaa '80. Tallinn: Eesti Raamat, 101-106.

Kurg, A. 2010. Mustamäe "inimlikustamine". Mati Undi "Sügisball” 1970. aastate kriitiliste arhitektuuripraktikate taustal. - Sügisball. Etü̈̈de nü̈̈liskultuurist 2. Ed. by V. Sarapik, P. Viires. Tartu Ülikooli Kirjastus, 28-38.

Langemets, A. 1980. Elu võimalikkusest. - Looming, No. 1, 129-132.

Lapin, L. 1980. Arhitektina Mati Undi Mustamäel. - Looming, No. 1, 132134.

Luik, V. 2005. Sõna on rohkem kui sõna. - Keel ja Kirjandus, No. 10, $777-$ 779. 
Mutt, M. 1986. Proosaimpressioone 1979. - M. Mutt, Kõik on üks ja seesama. Kirjandusest ja teatrist 1975-1985. Tallinn: Eesti Raamat, 268311.

Unt, M. 1979. Sügisball. Stseenid linnaelust. Tallinn: Eesti Raamat.

Unt, M. 1985. The Autumn Ball: Scenes of City Life. Tallinn: Perioodika, 1985.

Viires, P. 2003. Mustamäe Metamorphoses. - Koht ja paik / Place and Location: Studies in Environmental Aesthetics and Semiotics III. Ed. by V. Sarapik, K. Tüür. Proceedings of the Estonian Academy of Arts 14. Tallinn, 395-403.

Viires, P. 2008. Eesti kirjandus ja postmodernism. Tartu: Tartu Ülikooli Kirjastus.

The present article was written with the support of Estonian Science Foundation grant no. ETF7679 "Participatory Culture in Cyberspace: Literature and its Borders" and targeted financed research project no. SF0030054s08 "Rhetorical Patterns of Mimesis and Estonian Textual Culture". 